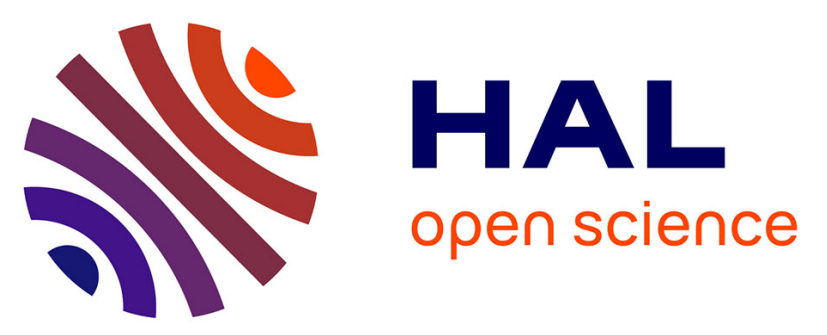

\title{
Iron-Catalyzed Enantioselective Intramolecular Inverse Electron-Demand Hetero Diels-Alder Reactions: An Access to Bicyclic Dihydropyran Derivatives
}

\author{
Jimmy Lauberteaux, Aurélien Lebrun, Arie van Der Lee, Marc Mauduit, \\ Renata Marcia de Figueiredo, Jean-Marc Campagne
}

\section{To cite this version:}

Jimmy Lauberteaux, Aurélien Lebrun, Arie van Der Lee, Marc Mauduit, Renata Marcia de Figueiredo, et al.. Iron-Catalyzed Enantioselective Intramolecular Inverse Electron-Demand Hetero Diels-Alder Reactions: An Access to Bicyclic Dihydropyran Derivatives. Organic Letters, 2019, 21 (24), pp.1000710012. 10.1021/acs.orglett.9b03752 . hal-02429682

\section{HAL Id: hal-02429682 https://hal.science/hal-02429682}

Submitted on 23 Nov 2020

HAL is a multi-disciplinary open access archive for the deposit and dissemination of scientific research documents, whether they are published or not. The documents may come from teaching and research institutions in France or abroad, or from public or private research centers.
L'archive ouverte pluridisciplinaire HAL, est destinée au dépôt et à la diffusion de documents scientifiques de niveau recherche, publiés ou non, émanant des établissements d'enseignement et de recherche français ou étrangers, des laboratoires publics ou privés. 


\section{Iron Catalyzed Enantioselective Intramolecular Inverse Electron-De- mand Hetero Diels-Alder Reactions: An Access to Bicyclic Dihydro- Pyran Derivatives}

Jimmy Lauberteaux, ${ }^{\mathrm{a}}$ Aurélien Lebrun, ${ }^{\mathrm{b}}$ Arie van der Lee, ${ }^{\mathrm{c}}$ Marc Mauduit, ${ }^{\mathrm{d}}$ Renata Marcia de Figueiredo, ${ }^{\mathrm{a}}$ and Jean-Marc Campagne ${ }^{\mathrm{a}^{*}}$

${ }^{a}$ Institut Charles Gerhardt Montpellier, UMR 5253, Univ Montpellier, CNRS, ENSCM, Ecole Nationale Supérieure de Chimie, 240 Avenue Emile Jeanbrau, 34296 Montpellier Cedex 5 (France).

b NMR Analysis: LMP, IBMM, Univ Montpellier, Montpellier, France.

${ }^{c}$ X-Ray Structures Analysis: Institut Européen des Membranes (IEM), UMR 5632, Univ Montpellier, CNRS - Place Eugène Bataillon, 34095 Montpellier Cedex 5, France.

d Univ Rennes, Ecole Nationale Supérieure de Chimie de Rennes, CNRS, ISCR UMR 6226, F-350oo Rennes, France.

KEYWORDS: Hetero Diels-Alder, Iron catalysis, Enantioselective catalysis

ABSTRACT: A highly enantioselective iron-catalyzed Intramolecular Inverse Electron-Demand Hetero Diels-Alder (IIEDHDA) reaction is reported. By using a chiral semicorrin ligand in the presence of 2,6 lutidine, good isolated yields and excellent enantioselectivities were observed (up to $96 \%$ ee). Thanks to the versatile post-functionalization of the acyl-imidazole moiety, this methodology represents a unique example of the straightforward construction of highly valuable enantioenriched bicyclic dihydropyran derivatives.

Among the powerful synthetically rich Diels-Alder family reactions, ${ }^{1}$ the intermolecular catalytic asymmetric [4+2] Inverse Electron-Demand Hetero Diels-Alder (IEDHDA) reaction gained a considerable success notably to access the prevalent 3,4-dihydropyran core. ${ }^{2}$ In contrast, very few examples have been reported that demonstrate high levels of enantiocontrol in the Intramolecular Inverse Electron-Demand Hetero Diels-Alder (IIEDHDA) reaction. Narasaka first explored this transformation with unsaturated oxazolidinone $\mathbf{1}$ in the presence of a stoichiometric amount of (Taddol) $\mathrm{TiCl}_{2}$. Unfortunately, despite high enantioselectivities, a mixture of Alder-ene $\mathbf{2}$ and IIEDHDA 3 products was formed (Scheme $1, a) .3$ In a series of papers, Tietze developed efficient domino Knoevenagel Hetero Diels-Alder from aldehydes and 1,3-dicarbonyl compounds. ${ }^{4}$ In the presence of an excess of diacetoneglucose-derived titanium catalyst, the IIEDHDA products $\mathbf{5}$ were obtained in good yields and cis diastereoselectivities with moderate to good enantioselectivities (30-88\% ee, Scheme 1, b). Wada described a catalytic enantioselective domino transesterification/intramolecular Diels-Alder sequence affording the trans-fused hydropyranopyrans 6 in good yields and excellent diastereo- and enantio-selectivities (69-76\% yield, 97-98\% ee, Scheme 1, c), with albeit narrow scope (3 examples). 5
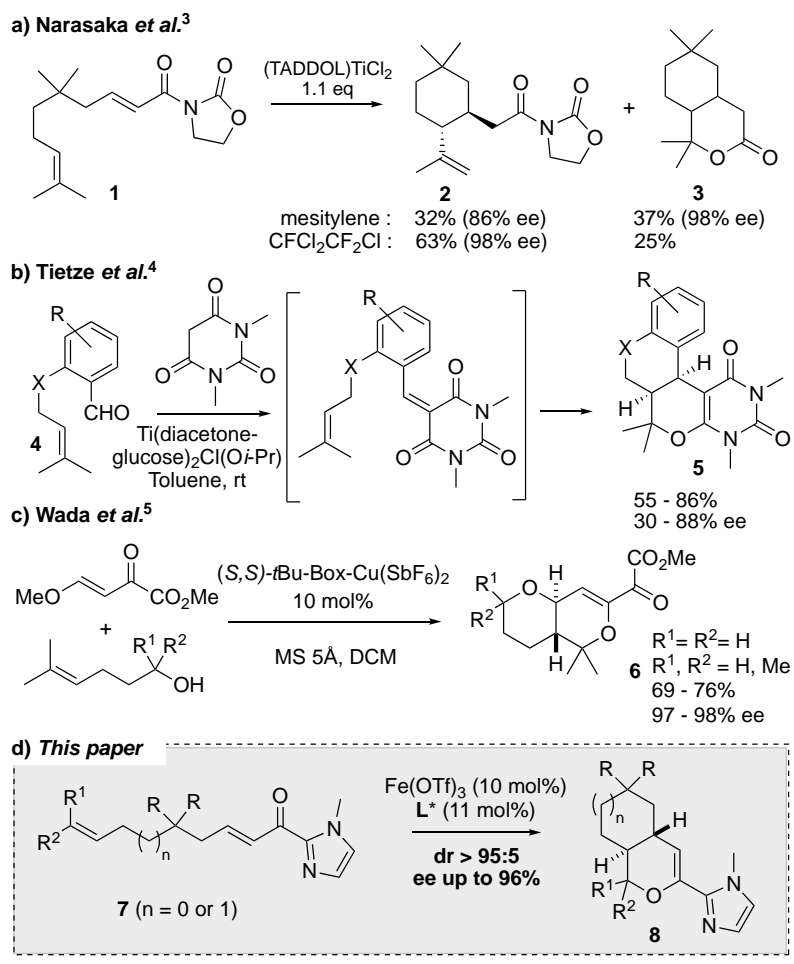

Figure 1. Enantioselective Intramolecular Inverse ElectronDemand Hetero Diels-Alder reactions. 
We would like to describe herein highly selective ironcatalyzed IIEDHDA reactions starting from unsaturated acyl-imidazoles derivatives $\mathbf{7}$ (Scheme $\mathbf{1}, \mathrm{d}$ ). Iron is an abundant, non-toxic, and inexpensive element and thus iron catalysis meets the requirements for sustainable and green chemistry. ${ }^{6}$

Based on our experience in asymmetric conjugate addition to unsaturated acyl-imidazoles, ${ }^{7}$ we were keen to exploit the unique properties of these ester/amide surrogates in IIEDHDA reactions. ${ }^{8}$ Investigations began with the IIEDHDA reaction of citral derivative $7 \mathbf{a}$ using several Lewis acids in the absence of chiral ligands (see Supplementary Information, SI, for details). Among the diverse metal salts tested, $\mathrm{Cu}(\mathrm{OTf})_{2}$ and $\mathrm{Fe}(\mathrm{OTf})_{3}$ proved to be the more promising ones leading to the IIEDHDA product 8a as a single diastereomer in 69 and $83 \%$ yields respectively (table 1, entries 1,2). Interestingly, only traces $(<5 \%)$ of the Alder-ene product 9a could be detected. As determined by ${ }^{1} \mathrm{H}$ NMR and further confirmed on X-Ray structures on post-transformed compounds (vide infra), 8a adopts a bicyclic trans junction as expected through a sterically favored anti TS usually observed for $E$-dienes. ${ }^{2 a-b}$

Table 1. Chiral ligand optimization

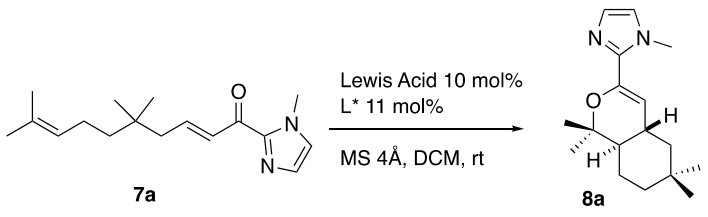

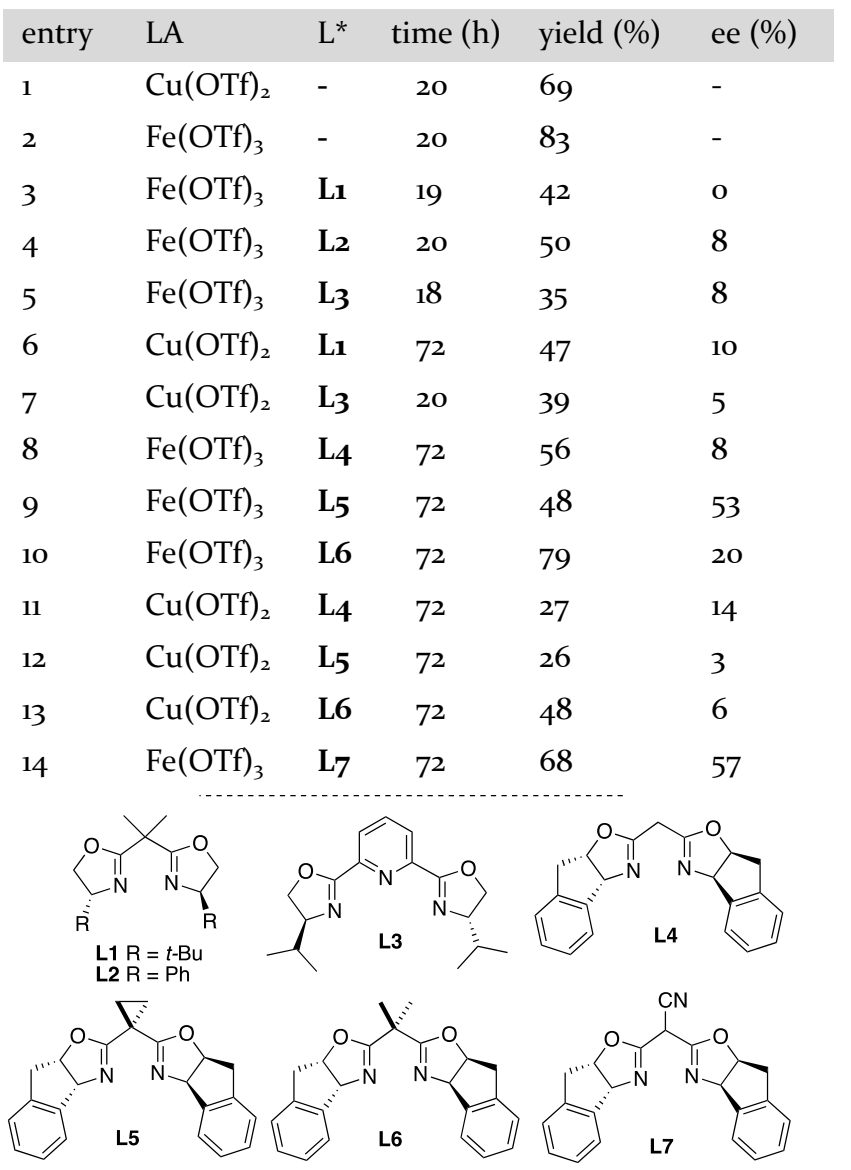

It is noteworthy that no reaction occurs when Weinreb amide or ethyl ester derivatives are involved, illustrating the peculiar properties of the acyl-imidazole. Indeed, acylimidazoles are more electron-withdrawing groups compared to esters and other ester-surrogates, and they are able via a double mode of coordination to warrant a defined transition state. ${ }^{8}$

Asymmetric reactions were thus next explored with $\mathrm{Cu}(\mathrm{OTf})_{2}$ and $\mathrm{Fe}(\mathrm{OTf})_{3}$ in the presence of most commonly used Box and Pybox L1-L6 ligands with however disappointing results (Table 2, entries 3-13). 9 The notable exception was observed with $\mathrm{Fe}(\mathrm{OTf})_{3} / \mathbf{L}_{\mathbf{5}}$ (entry 9) for which a $53 \%$ ee could be reached. All our further attempts to improve the selectivity by changing the reaction parameters (solvent, temperature, iron salts) proved anyway unsuccessful in our hands. It was anticipated that the presence of an electron withdrawing group on the bridging carbon of the bis(oxazoline) could enhance the reactivity of the metal complex..$^{10}$ This was confirmed by using $\mathbf{L}_{7}$ bearing a cyano group that produced the compound $8 \mathbf{a}$ in $68 \%$ isolated yield and improved $57 \%$ ee (entry 14). Anticipating that traces of triflic acid could promote a parallel and racemic catalytic cycle, the use of a base as additive was envisioned in the presence of $\mathrm{Fe}(\mathrm{OTf})_{3} / \mathbf{L}_{7}$ (Table 2). ${ }^{11}$

Table 2. Base as additive in the asymmetric IIEDHDA reaction with $7 \mathrm{a}$

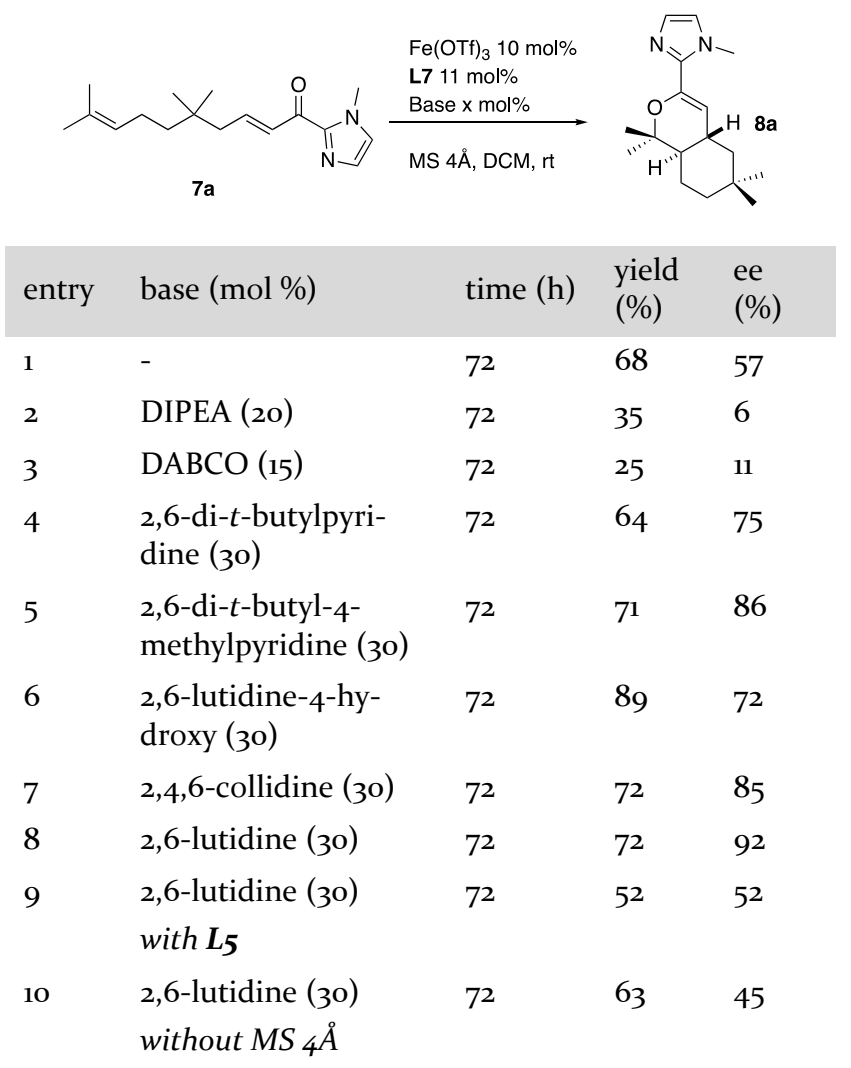

After a screening of several bases, a drastic improvement of enantioselectivity was observed with pyridine derivatives (entries 4-8) reaching a maximum of $92 \%$ ee in the presence of 2,6 lutidine (30 mol\%). Some other interesting observations could be draw from the optimization study. 
First, enantioselectivity dropped to $52 \%$ when using other chiral ligands such as L5 (entry 9). Second, the molecular sieves appeared essential to maintain the enantioselection (63\% yield, $45 \%$ ee, entry 10). At last, the catalyst can also be in-situ generated from $\mathrm{FeCl}_{3}$ and AgOTf with similar good results (see Supplementary Information, SI, for details).

After optimization of the IIEDHDA reaction with citral derivative 7a, the general scope was next explored (Scheme 1). When the chain length (6-6 vs 6-5 bicycles) was changed or bearing different substituents on the $\mathrm{R}^{4} / \mathrm{R}^{5}$ positions (alkyl chains, heteroatom or an acetal group), the reaction provided expected bicyclic compounds 8a-e in good yields and stereoselectivities ( $\mathrm{dr}>95: 5 ; 89 \%-96 \%$ ee) with the exception of $8 \mathbf{e}(\mathrm{dr} 60: 40)$. In this case, both separable diastereomers could be obtained in $92 \%$ ee. Concerning the 5,6-fused ring systems (compounds $\mathbf{8 b}-\mathbf{d}$ ), the trans configuration could be ascertained by analyzing the $\mathrm{H}_{4} \mathrm{NMR}$ signal ( $\mathrm{H}$ close to the double bond at the ring junction): For example in $\mathbf{8 b}$, the signal is a dddd with coupling constants of $12.1 ; 11.1 ; 7.2$ and 2.0 Hz. The attribution of each coupling constant is as followed: $12.1\left(\mathrm{H}_{4}\right.$-Hbicyclic), $11.1\left(\mathrm{H}_{4}-\mathrm{CH}_{\text {trans }} \mathrm{H}^{\prime}\right)$, 7.2 ( $\left.\mathrm{H}_{4}-\mathrm{CHH}_{\text {cis }}^{\prime}\right), 2.0\left(\mathrm{H}_{4}-\mathrm{H}_{\text {alkene }}\right)$. The large coupling constant is consistent with a trans relationship along the ring junction. Finally, we also observed that substrate $\mathbf{7}$ possessing a farnesyl chain $\left(\mathrm{R}^{1} * \mathrm{R}^{2}\right)$ afforded product $8 \mathrm{f}$ in $69 \%$ yield as a single diastereomer $(\mathrm{dr}$ $>$ 95:5) and high enantioselectivity (93\% ee).

Scheme 1. Scope of the asymmetric IIEDHDA reaction

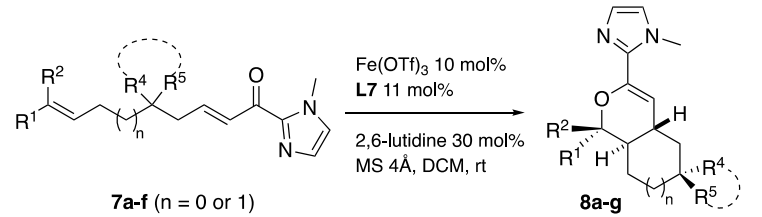

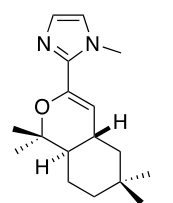

$8 \mathrm{a}$

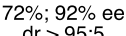

$\mathrm{dr}>95: 5$

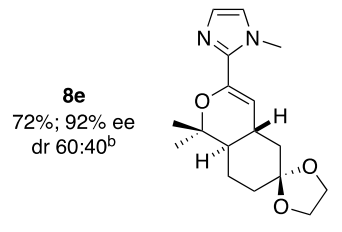

${ }^{\mathrm{a}} 15 \mathrm{~mol} \%$ of $\mathrm{Fe}(\mathrm{OTf})_{3}$ were used. ${ }^{\mathrm{b}} 92 \%$ ee was also observed for the minor cis diastereomer.

A more surprising result was observed with compounds $7 \mathrm{~g}$ bearing a remote cyclopropylidene unit. The IIEDHDA product $\mathbf{8 g}$ was not observed and compound 10 was isolated in $90 \%$ yield ( $1 \mathrm{mmol}$ scale) as a single diastereomer. The structure of 10 is rather complex embedding $3^{-}, 4^{-}, 5^{-}$ (spiro) and 6-membered cycles (Scheme 2). Structural determination proved challenging and was finally ascertained using a ${ }^{13} \mathrm{C}$ NMR INADEQUATE sequence (ee SI).
Scheme 2. Rearrangement of $7 \mathrm{~g}$ in IIEDHDA reaction conditions

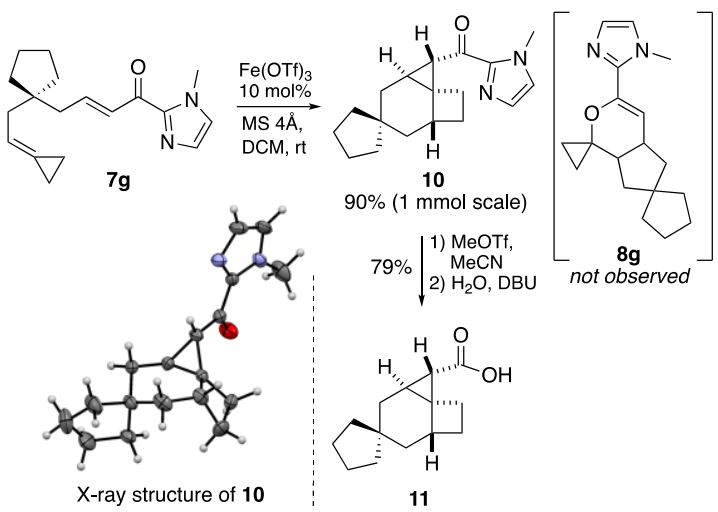

Its structure was unambiguously confirmed by single crystal X-Ray diffraction studies. Moreover, the acyl-imidazole was further easily transformed into the corresponding carboxylic acid $\mathbf{1 1}$ in $79 \%$ yield. ${ }^{8}$ Finally, in the presence of $\mathbf{L} 7$-lutidine, compound 10 could be isolated in $85 \%$ yield and $37 \%$ ee. The formation of 10 can tentatively be explained through two successive Wagner-Meerwein rearrangements (See mechanistic proposal in SI).

Scheme 3. IIEDHDA reaction with $(R)$ - and $(S)$-enantiomer of citronellal derivative $7 \mathrm{~h}$

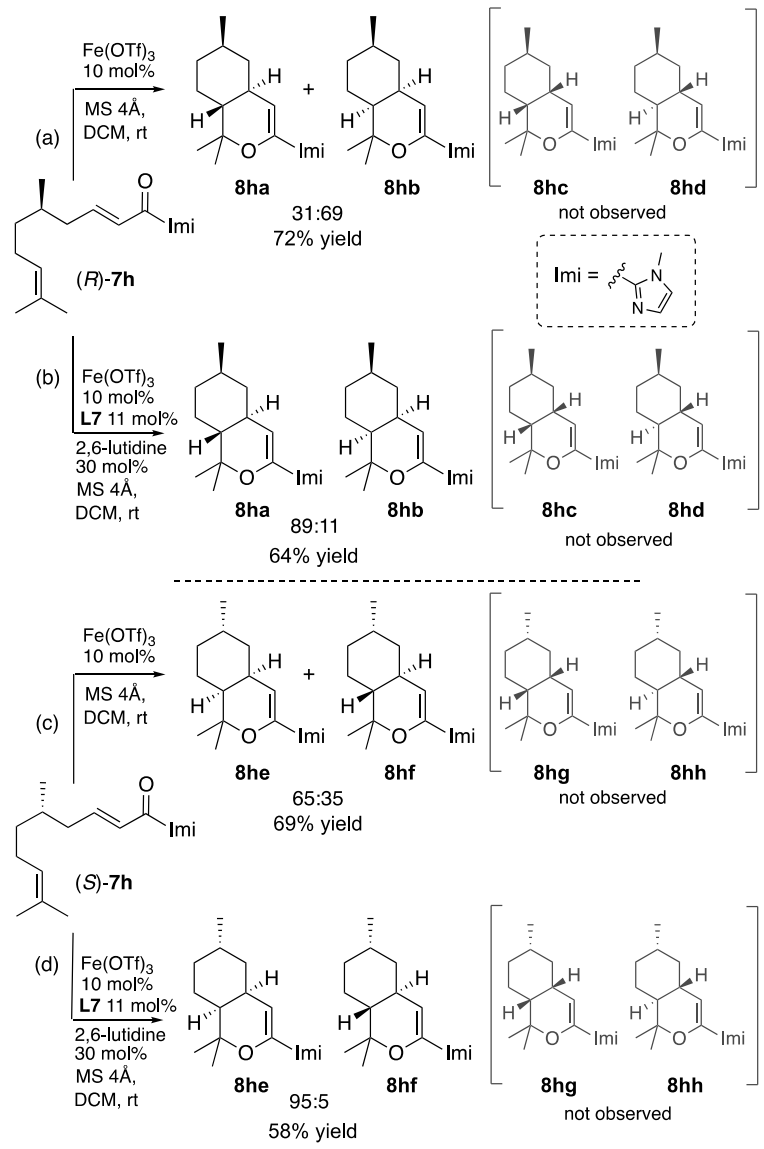

We next turned our attention to citronellal derivatives ${ }_{7} \mathbf{h}$ bearing a methyl group in the $\delta$ position (Scheme 3 ). 
These substrates are more challenging because the introduction of a stereogenic center could potentially lead to 4 diastereomers and induce match/mismatch pairs. Moreover, they lack beneficial Thorpe-Ingold effect. Starting from the $(R)$ enantiomer, the IIEDHDA reaction was first carried out in the absence of chiral ligand (Scheme 3, a). In this case, only two diastereomers $\mathbf{8 h a}$ and $\mathbf{8 h b}$ were observed in a 31:69 ratio by ${ }^{1} \mathrm{H}$ NMR on the crude material. Moving to the optimized enantioselective conditions, a reverse 89:11 ratio could be observed (Scheme 3, b). The structure of the major diastereomer 8 ha could be unambiguously confirmed by ${ }^{1} \mathrm{H}$ NMR NOESY experiments (for the determination of the structure of minor diastereomers, see SI). With the $(S)$ enantiomer under achiral conditions $\left(\mathrm{Fe}(\mathrm{OTf})_{3}, \mathrm{DCM}, \mathrm{rt}\right)$, two other diastereomers 8 he and $\mathbf{8 h f}$ were observed in a 65:35 ratio (determined by ${ }^{1} \mathrm{H}$ NMR on the crude material, Scheme 3, c). In chiral conditions $\left(\mathrm{Fe}(\mathrm{OTf})_{3}, \mathbf{L}_{7}\right.$, lutidine), an improved 95:5 ratio of the same two diastereomers 8 he and $\mathbf{8 h f}$ could be observed with $58 \%$ isolated yield (Scheme 3, d). The structure of 8 he proved more difficult to establish. From NMR studies (see SI), it appears that 8he adopts a bicyclic cis junction, with the two protons at the ring junction being cis to the stereogenic methyl group. These two experiences highlight the prominent role of chiral ligand $\mathbf{L}_{7}$ in the double stereodifferentiation with these chiral substrates. The scaleup reaction was next attempted on acyl-imidazoles $7 \mathbf{a}$ and $(S)$ - 7 h. Moving from a 0.2 to $1.0 \mathrm{mmol}$ scale was found experimentally more practical and beneficial in terms of isolated yield ( $84 \%$ vs $72 \%$ and $90 \%$ vs $58 \%$ respectively) with no change in the stereoselectivity (enantio- or diastereoselectivity) issues.

\section{Scheme 4. IIEDHDA products post-functionalization}

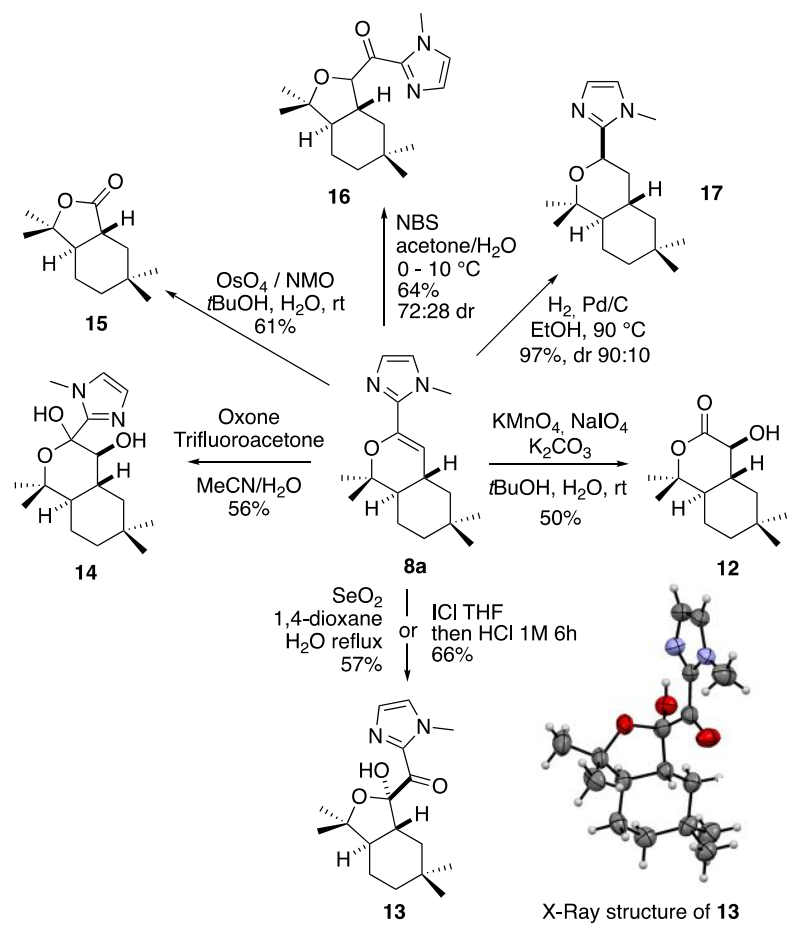

The IIEDHDA products 8 possess an usual bicyclic structure with a pending imidazolyl group and thus offer many possibilities for synthetic post-transformations. Acid-mediated direct transformation of the imidazole ring (or the imidazolium salt after methylation with MeOTf) in 8a proved unsuccessful under various conditions. We thus next explored conditions for the double bond oxidation. In the presence of $\mathrm{KMnO}_{4} / \mathrm{NaIO}_{4}$, the $\alpha$-hydroxy lactone 12 was obtained in $50 \%$ yield as a single diastereomer. The oxidation of 8a in the presence of $\mathrm{SeO}_{2}$ led to the corresponding diketone isolated as the acetal $\mathbf{1 3}$ as a single diastereomer. The structure was ascertained by an X-Ray analysis and also confirmed the trans relationship of the two hydrogens at the ring junction. Interestingly, the same compound 13 could be obtained from 8 a using $\mathrm{ICl}$ in $66 \%$ yield. Epoxidation of the double bond was next attempted out using oxone and trifluoroacetone, ${ }^{12}$ but compound 14 resulting from a dihydroxylation reaction was obtained in $56 \%$ yield as a single diastereomer. By using $\mathrm{OsO}_{4} / \mathrm{NMO}$, lactone 15 was isolated in $61 \%$ yield. In the presence of NBS, the ring contraction product 16 was obtained in $64 \%$ yield in a 72:28 dr. Finally, the enol ether double bond could be reduced in the presence of $\mathrm{Pd} / \mathrm{C}$ to give compound $\mathbf{1 7}$ in $97 \%$ yield (90:10 dr).
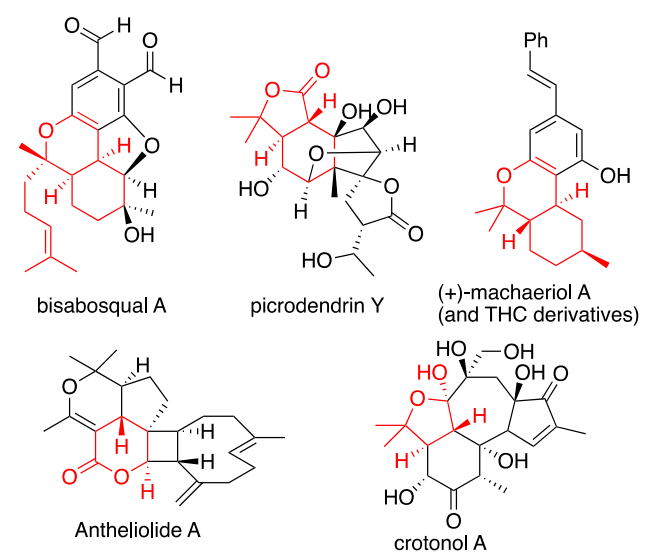

Figure 2. Natural Products embedding dihydropyran derivatives $8 b$ and post-transformed products 12-17.

It should be emphasized that bicyclic dihydropyran derivatives 8 and post-transformed products 12-17 are present in a wide range of bioactive natural products, as illustrated in figure $2 .{ }^{13}$ 
Scheme 5. Determination of the absolute configurations

(a)

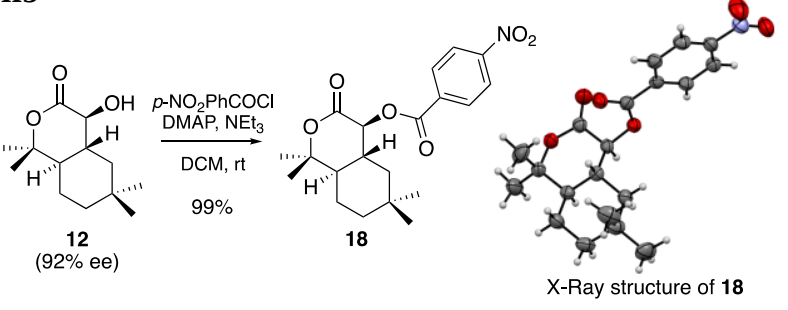

(b)

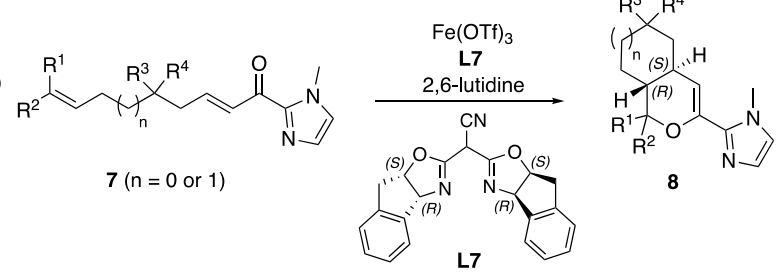

The determination of absolute configurations of IIEDHDA products $\mathbf{8}$ could be finally obtained via the derivatization of enantiomerically enriched $\mathbf{1 2}$ ( $92 \%$ ee) to the corresponding $p-\mathrm{NO}_{2}$ phenyl ester $\mathbf{1 8}$ allowing the formation of a crystalline compound (Scheme 5 , a). An X-ray structure for $\mathbf{1 8}$ was obtained confirming the relative stereochemistry determined by ${ }^{1} \mathrm{H}$ NMR but also establishing absolute configurations. It should be emphasized that this experiment confirms the absolute configurations observed in 8ha (obtained from $(R)-7 \mathbf{h})$. Accordingly, the absolute stereochemistries for compounds $\mathbf{8}$ obtained from $\mathrm{Fe}(\mathrm{OTf})_{3} / \mathbf{L}_{7}$ (obtained from $(1 R, 2 S)-(+)$-cis-1-amino-2-indanol)) were thus tentatively assigned by analogy (Scheme 5, b).

Finally, an intermolecular version of the hetero Diels-Alder reaction of acyl-imidazoles $19(\mathrm{R}=\mathrm{Me}$ or $\mathrm{Ph})$ with dihydrofuran led to the Diels-Alder products 20 in low yields but promising enantioselectivities (Scheme 6).

\section{Scheme 6. Asymmetric intermolecular reactions}

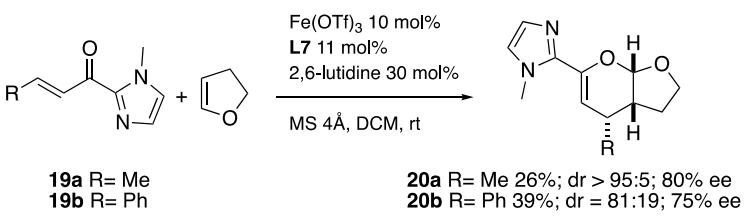

In summary, we have developed a highly enantioselective iron-catalyzed Intramolecular Inverse Electron-Demand Hetero Diels-Alder (IIEDHDA) reaction using $C_{2}$ symmetric semicorrin ligand and 2,6-lutidine. This ironcatalyzed reaction generates enantioenriched bicyclic dihydropyran derivatives in good yields and excellent diastereo- and enantio-selectivities. These compounds can be further easily transformed into a large range of valuable bicyclic heterocycles. Further mechanistic investigations and DFT calculations are currently ongoing in our laboratory to unveil the role of the base in these transformations, and determine the stepwise vs concerted character of this [4+2] cycloaddition, as we envision that this catalytic system will inspire future studies in iron-catalyzed asymmetric transformations.

\section{ASSOCIATED CONTENT}

\section{AUTHOR INFORMATION}

\section{Corresponding Author}

* E-mail: jean-marc.campagne@enscm.fr

\section{Author Contributions}

The manuscript was written through contributions of all authors.

\section{Notes}

The authors declare no competing financial interests.

\section{ACKNOWLEDGMENT}

The project was supported by funds from the ENSCM, the CNRS and the Fondation pour le développement de la chimie des substances naturelles et ses applications (JL PhD grant). Special thanks to Takasago Company for a generous gift of citronellal.

\section{REFERENCES}

(1) (a) Corey, E. J. Catalytic Enantioselective Diels-Alder Reactions: Methods, Mechanistic Fundamentals, Pathways, and Applications. Angew. Chem. Int. Ed. 2002, 41, 1650-1667. (b) Juhl, M.; Tanner, D. Recent Applications of Intramolecular Diels-Alder Reactions to Natural Product Synthesis. Chem. Soc. Rev. 2009, 38 , 2983-2992. (c) Heravi, M. M.; Vavsari, V. F. Recent Applications of Intramolecular Diels-Alder Reaction in Total Synthesis of Natural Products. RSC Advances 2015, 5, 50890-50912.

(2) (a) Pałasz, A. Recent Advances in Inverse-Electron-Demand Hetero-Diels-Alder Reactions of 1-Oxa-1,3-Butadienes. Top. Curr. Chem. 2016, 374, 24. (b) Tietze L.F. ; Kettschau G. Hetero DielsAlder Reactions in Organic Chemistry. Top Curr. Chem 1997, 189, 1-120. (c) Jiang, X.; Wang, R. Recent Developments in Catalytic Asymmetric Inverse-Electron-Demand Diels-Alder Reaction. Chem. Rev. 2013, 113, 5515-5546. (d) Desimoni, G.; Faita, G.; Quadrelli, P. Forty Years after "Heterodiene Syntheses with $\alpha, \beta$-Unsaturated Carbonyl Compounds": Enantioselective Syntheses of 3,4Dihydropyran Derivatives. Chem. Rev. 2018, 118, 2080-2248.

(3) (a) Narasaka, K.; Hayashi, Y.; Shimada, S. Asymmetric Intramolecular Ene Reaction Catalyzed by a Chiral Titanium Alkoxide. Chem. Lett. 1988, 17, 1609-1612. (b) Narasaka, K.; Hayashi, Y.; Shimada, S.; Yamada, J. Asymmetric Intramolecular Ene Reaction Catalyzed by a Chiral Titanium Reagent and Synthesis of (-)- $\varepsilon-C a-$ dinene. Isr. J. Chem. 1991, 31, 261-271.

(4) (a) Tietze, L. F.; Brumby, T.; Brand, S.; Bratz, M. Inter- and Intramolecular Hetero Diels-Alder Reactions, XXI. Intramolecular Hetero Diels-Alder Reaction of Alkylidene-1,3-Dicarbonyl Compounds. Experimental Evidence for an Asymmetric Transition State. Chem. Ber. 1988, 121, 499-506. (b) Tietze, L. F.; Brand, S.; Brumby, T.; Fennen, J. Intramolecular Hetero-Diels-Alder Reactions of Oxadienes: Influence of Substituents of the Tether on the Diastereoselectivity. Angew. Chem. Int. Ed. Eng. 1990, 29, 665667. (c) Tietze, L. F.; Saling, P. Enantioselective Sequential Transformations by Use of Metal Complexes: Tandem-KnoevenagelHetero-Diels-Alder Reactions with New Chiral Lewis Acids. Chirality 1993, 5, 329-333. (d) Sabitha, G.; Fatima, N.; Reddy, E. V.; Yadav, J. S. First Examples of Proline-Catalyzed Domino Knoevenagel/Hetero-Diels-Alder/Elimination Reactions. Adv. Synth. Catal. 2005, 347, 1353-1355. 
(5) Wada, E.; Koga, H.; Kumaran, G. A Novel Catalytic Enantioselective Tandem Transetherification-Intramolecular Hetero Diels-Alder Reaction of Methyl (E)-4-Methoxy-2-Oxo-3-Buteno-

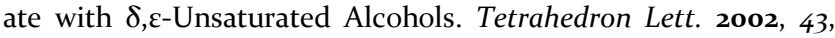
9397-9400.

(6) Pellissier, H. Recent developments in enantioselective ironcatalyzed transformations. Coord. Chem. Rev. 2019, 386, 1-31.

(7) (a) Drissi-Amraoui, S.; Morin, M. S. T.; Crévisy, C.; Baslé, O.; de Figueiredo, R. M.; Mauduit, M.; Campagne, J.-M. Copper-Catalyzed Asymmetric Conjugate Addition of Dimethylzinc to AcylN-methylimidazole Michael Acceptors: A Powerful Synthetic Platform. Angew. Chem. Int. Ed. 2015, 54, 11830-11834. (b) DrissiAmraoui, S.; Schmid, T. E.; Lauberteaux, J.; Crévisy, C.; Baslé, O.; de Figueiredo, R. M.; Halbert, S.; Gérard, H.; Mauduit, M.; Campagne, J.-M. Copper-Catalyzed Asymmetric Conjugate Addition of Dimethylzinc to Acyl-N-methylimidazole Michael Acceptors: Scope, Limitations and Iterative Reactions. Adv. Synth. Catal. 2016, 358, 2519-2540. (c) Lauberteaux, J.; Crévisy, C.; Baslé, O.; de Figueiredo, R. M.; Mauduit, M.; Campagne, J.-M. Copper-Catalyzed Asymmetric Conjugate Additions of Bis(Pinacolato)Diboron and Dimethylzinc to Acyl-N-Methylimidazole Michael Acceptors: A Highly Stereoselective Unified Strategy for $1,3,5, \ldots \mathrm{n}$ (OH, Me) Motif Synthesis. Org. Lett. 2o19, 21, 1872-1876.

(8) For seminal work in asymmetric catalysis, see: (a) Evans, D.A.; Fandrick, D. K.; Song, H.-J. Enantioselective Friedel-Crafts Alkylations of $\alpha, \beta$-Unsaturated 2-Acyl Imidazoles Catalyzed by Bis(oxazolinyl)pyridine-Scandium(III) Triflate Complexes. J. Am. Chem. Soc. 2005, 127, 8942-8943. (b) Evans, D.A.; Fandrick, D. K. Catalytic Enantioselective Pyrrole Alkylations of $\alpha, \beta$-Unsaturated 2-Acyl Imidazoles. Org. Lett. 2006, 8, 2249-2252. For reviews, see: (c) Lauberteaux, J.; Pichon, D; Baslé, O.; Mauduit, M.; de Figueiredo, R. M.; Campagne, J.-M. Acyl-Imidazoles: A Privileged Ester Surrogate for Enantioselective Synthesis. ChemCatChem. 2019, 11, doi: 10.1002/cctc.201900754. (d) Mansot, J., Vasseur, J.-J.; Arseniyadis, S.; Smietana, M. $\alpha, \beta$-Unsaturated 2-Acyl-Imidazoles in Asymmetric Biohybrid Catalysis. ChemCatChem 2019, 11, doi: 10.1002/cctc.201900743.
(9) (a) Johnson, J. S.; Evans, D. A. Chiral Bis(Oxazoline) Copper(II) Complexes: Versatile Catalysts for Enantioselective Cycloaddition, Aldol, Michael, and Carbonyl Ene Reactions. Acc. Chem. Res. 2000, 33, 325-335. (b) Ollevier, T. Iron bis(oxazoline) complexes in asymmetric catalysis. Catal. Sci. Technol. 2016, 6, $41-48$.

(10) (a) Pfaltz, A. Chiral Semicorrins and Related Nitrogen Heterocycles as Ligands in Asymmetric Catalysis. Acc. Chem. Res. 1993, 26, 339-345. (b) Nolin, K. A.; Ahn, R. W.; Kobayashi, Y.; Kennedy-Smith, J. J.; Toste, F. D. Enantioselective Reduction of Ketones and Imines Catalyzed by (CN-Box)ReV-Oxo Complexes. Chem. - A Eur. J. 2010, 16, 9555-9562.

(11) The exact role of the added base is not yet understood. Efforts to crystallize the $\mathrm{Fe}(\mathrm{OTf})_{3} / \mathrm{L}_{7}$ or $\mathrm{Fe}(\mathrm{OTf})_{3} / \mathrm{L} 7 / 2$,6-lutidine catalytic systems were unsuccessful in our hands only leading to the crystalline $\mathrm{L}^{\circ} \mathrm{TfOH}$ salt, catalytically unactive in the absence of iron.

(12) Yang, D.; Wong, M.-K.; Yip, Y.-C. Epoxidation of Olefins Using Methyl(Trifluoromethyl)Dioxirane Generated in Situ. J. Org. Chem. 1995, 6o, 3887-3889.

(13) (a) Green, D.; Carmely, S.; Benayahu, Y.; Kashman, Y. Antheliolide A \& B: Two New C24-Acetoacetylated Diterpenoids of the Soft Coral Anthelia Glauca. Tetrahedron Lett. 1988, 29, 16051608. (b) Smith, A. B.; Carroll, P. J.; Kashman, Y.; Green, D. Revised Structures of Antheliolides A and B. Tetrahedron Lett. 1989, 30, 3363-3364. (c) Wang, J.; Qin, L.; Zhao, B.; Cai, L.; Zhong, Z.; Liu, Y.; Zhou, X. Crotonols A and B, Two Rare Tigliane Diterpenoid Derivatives Against $\mathrm{K}_{562}$ Cells from Croton Tiglium. Org. Biomol. Chem. 2019, 17, 195-202. (d) Muhammad, I.; Li, X.-C.; Dunbar, D. C.; ElSohly, M. A.; Khan, I. A. Antimalarial (+)-trans-Hexahydrodibenzopyran Derivatives from Machaerium Multiflorum. J. Nat. Prod. 2001, 64, 1322-1325. (e) Minagawa, K.; Kouzuki, S.; Nomura, K.; Kawamura, Y.; Tani, H.; Terui, Y.; Nakai, H. Bisabosquals, Novel Squalene Synthase Inhibitors. J. Antibiot. 2001, 54, 890-895. (f) Suzuki, Y.; Koike, K.; Nagahisa, M.; Nikaido, T. New Picrotoxane Terpenoids from Picrodendron Baccatum. Tetrahedron 2003, 59, 6019-6025. 